\title{
Optimal Portfolio Selection of Wind Power Plants Using a Stochastic Risk-Averse Optimization Model, Considering the Wind Complementarity of the Sites and a Budget Constraint
}

\author{
Luiz A. S. Camargo, Laís D. Leonel, Pedro S. Rosa, Dorel S. Ramos* \\ Department of Power Engineering and Electrical Automation, University of São Paulo (USP), São Paulo, Brazil \\ Email: ^dorelram@usp.br
}

How to cite this paper: Camargo, L.A.S., Leonel, L.D., Rosa, P.S. and Ramos, D.S. (2020) Optimal Portfolio Selection of Wind Power Plants Using a Stochastic Risk-Averse Optimization Model, Considering the Wind Complementarity of the Sites and a Budget Constraint. Energy and Power Engineering, 12, 459-476.

https://doi.org/10.4236/epe.2020.128028

Received: May 8, 2020

Accepted: August 9, 2020

Published: August 12, 2020

Copyright (๑) 2020 by author(s) and Scientific Research Publishing Inc. This work is licensed under the Creative Commons Attribution International License (CC BY 4.0).

http://creativecommons.org/licenses/by/4.0/

\begin{abstract}
This work focuses on the best financial resources allocation to define a wind power plant portfolio, considering a set of feasible sites. To accomplish the problem formulation and solution, the first step was to establish a long-term wind series reconstruction methodology for generating scenarios of wind energy, applying it to study five different locations of the Brazilian territory. Secondly, a risk-averse stochastic optimization model was implemented and used to define the optimal wind power plant selection that maximizes the portfolio financial results, considering an investment budget constraint. In a sequence, a case study was developed to illustrate a practical situation of applying the methodology to the portfolio selection problem, considering five wind power plants options. The case study was supported by the proposed optimization model, using the scenarios of generation created by the reconstruction methodology. The obtained results show the model performance in terms of defining the best financial resources allocation considering the effect of the complementarity between sites, making it feasible to select the optimal set of wind power plants, characterizing a wind plant optimal portfolio that takes into account the budget constraint. The adopted methodology makes it possible to realize that the diversification of the portfolio depends on the investor risk aversion. Although applied to the Brazilian case, this model can be customized to solve a similar problem worldwide.
\end{abstract}

\section{Keywords}

Wind Power Plant, Portfolio Selection, Risk Aversion, Stochastic Optimization 


\section{Introduction}

The renewable capacity expansion around the World has increased over the past years. In 2019, the additions have taken the renewable share of all global power capacity to $34.7 \%$ [1]. In case of Brazil, wind energy accounted for $9 \%$ of total system capacity in 2019 [2]. The growth is justified by the countries' attempt to transform their electricity matrix cleaner, changing from fossil fuel plants to renewable sources, and by the lower technological renewable costs when compared to years before.

Despite the benefits of cleaner and low cost energy, the renewable generation brings important issues to system operation due to its natural intermittency and seasonality characteristics [3]. The studies [4] [5] show that high renewable sources penetration on the power system requires the implementation of system flexibility mechanisms such as controlled units, ancillary services, market design changes and storage services.

Other issue related to renewable sources is the financial risk of its cash flow that may discourage new investors. It can be explained by periods where the renewable generation curve does not meet the selling volumes contracts, leading to involuntary exposures to the short-term market.

One alternative to mitigate this issue is to explore portfolios composed by power plants with different seasonal generation patterns where the complementary effect between the plants can be used for financial risk management.

Several works demonstrate that the complementary effect resulting from the geographical or technological diversification of renewable generation [6] [7] [8] [9] [10] can mitigate the generation risk and improve the financial results under the risk-return perspective.

Therefore, for decisions of new investments in renewable generation, that involves uncertain variables as generation and spot price, is essential an appropriated risk analysis model with representation of stochastic behavior, that can be obtained by applying stochastic programming [11] techniques with risk metrics [12] and risk-aversion approaches [13] in the formulation, resulting in a model with risk-return analysis where the decision is taken by the expected return and the risk weighted by a parameter that represents the risk aversion profile of the decision maker.

A methodology to represent the stochasticity of wind generation into the medium-term planning of Brazilian system can be seen in [14]. The quoted study uses the methodology of wind time series reconstruction presented by [15].

In this context, this work focuses on searching the best financial resources allocation for optimal wind power plants portfolio selection and proposes a long-term wind series reconstruction methodology for generating scenarios of wind energy by improving the methodology present in [15], and proposes a risk-averse stochastic optimization model to define the optimal wind power plant selection.

This paper is organized as follows. Section 2 details the methodology for 
long-term wind series reconstruction and applies it to estimate the generation scenarios of five sites located in the Brazilian territory, taking into account the Vortex and NCEP/NCAR mesoscale data set of these locations. Section 3 describes the risk-averse stochastic optimization model, which aims to define the optimal portfolio selection of wind power plants, considering the wind complementarity of the sites and budget constraint. An application case is presented in this section, investigating the effect of risk aversion on the decision, under different CAPEX premises. Finally, Section 4 presents the main conclusions of the paper.

\section{Long-Term Wind Series Treatment}

For wind energy investment analysis using stochastic programming models, it is essential to work with long-term scenarios of wind generation to guarantee the results quality, reliability and representativeness. For this reason, data processing activities and series characterization are incorporated into the time series reconstruction (wind speed/wind generation) methodologies for long-term scenarios.

It is worthwhile to realize that this work proposes improvements to the methodology presented in [15], which aims the reconstruction of wind time series for long term analysis. The innovation is associated with the modeling and data analysis processes. The methodology addresses the equations and processes to Pandas scientific data model. The library is coded in Python computer language, providing a better and quite robust time-series data analysis by applying the codes available in the library. For more details about Data Analysis see [16].

\subsection{Methodology for the Reconstruction of Wind Time Series}

The methodology proposed in this work aims at the reconstruction of long-term wind generation series. To this end, it also includes the basic activities of processing wind speed data from series originated from mesoscale data.

The main challenge of the reconstruction process is related to the application of the methodology developed by [15], for the extension of a shorter time series ( 1 - 30 years) to a longer time series ( $>60$ years), in order to obtain an extended data set to be applied in the process of creating scenarios with associated probability of occurrence, preserving the statistical parameters of the reference series.

The methodology of wind time series reconstruction (speed and generation) can be explained partitioning the whole process in three main steps: 1) selection and validation of time series, 2) reconstruction of the daily series based on the medium term reference series characteristics (e.g.: Vortex), 3) daily generation estimation based on the reconstructed series.

The methodology Steps are presented in detail as follows and can be summarized as shown in the flowcharts of Figure 1, Figure 2 and Figure 3. In the example, two mesoscale long-term historical wind speed time series are used: NCAR (National Center for Atmospheric Research) [17] and Vortex (Weather Research \& Forecasting Model) [18]. 


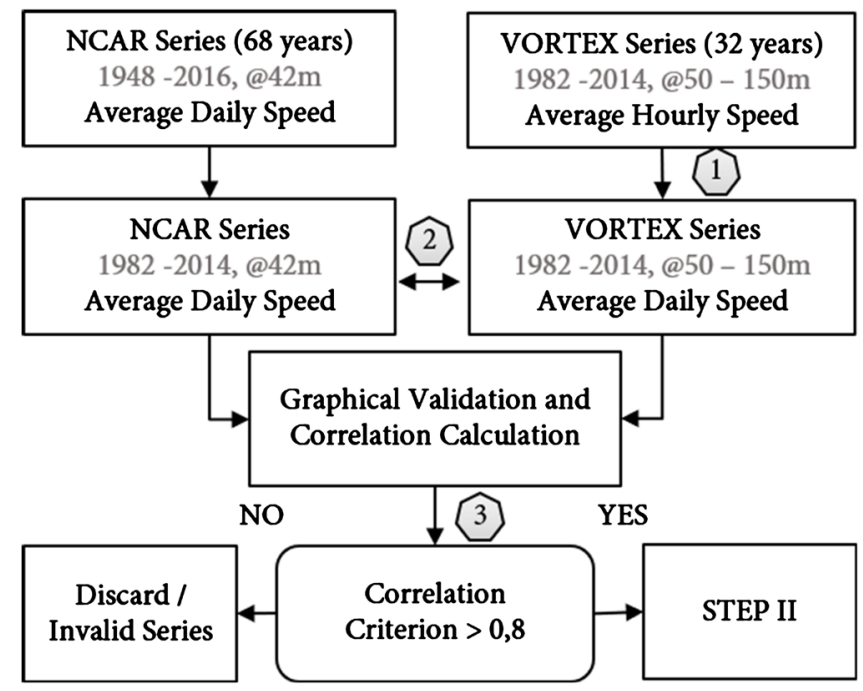

Figure 1. Selection and validation of time series.

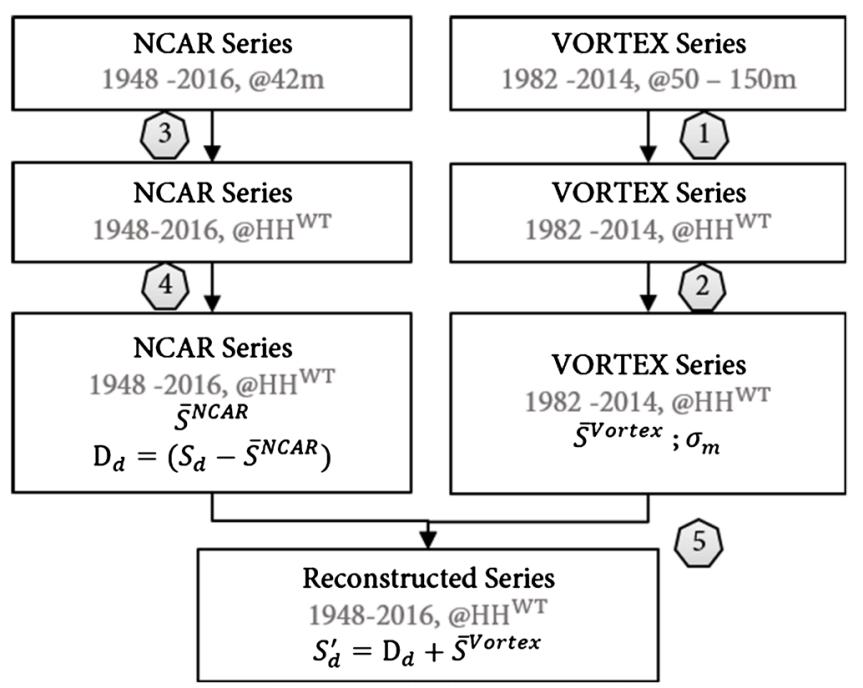

Figure 2. Reconstruction of the daily series based on the vortex series characteristics.

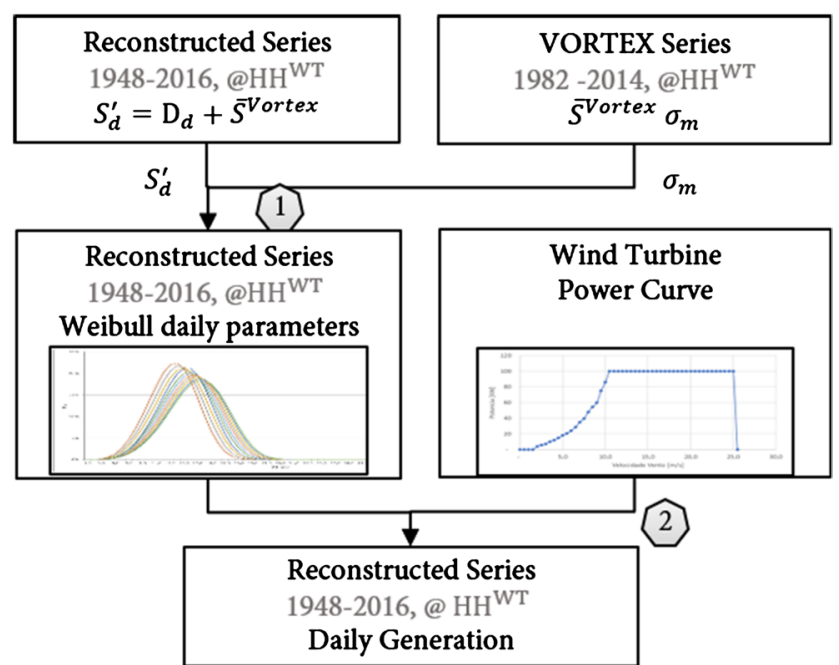

Figure 3. Daily generation based on the reconstructed series. 


\section{STEP I: Selection and Validation of Time Series}

Step I aims to select and validate the time series to be used in the reconstruction process. Figure 1 shows the procedures applied in this step, using NCAR Series (1948-2016) and Vortex Series (1982-2016) as an example.

It is important to evidence that NCAR and Vortex are mesoscale long-term historical wind speed time series with different horizons and time scale. The NCAR series has 68-year horizon and data integrated at every 6 hours, while the Vortex has a 32-year horizon and data integrated at every 1 hour.

The practical difficulties coming from data alignment and combination between these data sets are overcome with the set of tools available in Pandas Library, e.g. resample, merge and group-by methods.

In Step I, these methods are applied for the wind speed time series validation aiding the following procedures:

1) Calculation of the average daily speeds for both series NCAR e Vortex;

2) Transformation of NCAR e Vortex series into the same analysis period (start-end);

3) Validation of all series with cross-correlation greater than 0.8 ;

4) In case of validation, proceed to Step II. Otherwise, other series (data sources) are evaluated and the procedures are repeated.

STEP II: Reconstruction of the daily series based on the Vortex series characteristics

Step II focuses on the daily series reconstruction process based on the statistical characteristics of the base series (Vortex). Figure 2 illustrates the flowchart with the main procedures.

The procedures adopted in this Step II can be described as follows:

1) Vertical extrapolation of the base series (Vortex) to the hub height of the wind turbine $\left(H H^{W T}\right)$;

2) Vortex statistical analysis from the hourly speed, calculating the average speed ( $\bar{S}^{\text {Vortex }}$ ) and the monthly standard deviations $\left(\sigma_{m}\right)$ of the series;

3) Vertical extrapolation of the reference series (NCAR) based on the calculation of the power law exponent $(n)$, considering a statistical adjustment based on speeds with different heights of the base series;

4) NCAR statistical analysis using the extrapolated reference series, calculating the average speed $\left(\bar{S}^{N C A R}\right)$ and daily variability $\left(D_{d}\right)$ (distance between daily speed and long-term average speed);

5) Reconstruction of the daily series considering the daily variability of the NCAR (1948-2016) and the average speed of the Vortex (1982-2014), the series for the entire horizon 1948-2016 ( $\left.S_{d}^{\prime}\right)$.

Equation (1) presents the required calculation for vertical extrapolation of the reference series (NCAR) and Equation (2) provides the power law exponent (n) adjusted as proposed in [15] and adopted to feed the Pandas data model.

$$
\bar{S}^{N C A R}=S^{N C A R} \cdot\left(\frac{H G^{W T}}{H G^{N C A R}}\right)^{n}
$$




$$
n=\frac{\log \left(\frac{\bar{S}^{\text {VORTEX }}}{\bar{S}^{N C A R}}\right)}{\log \left(\frac{H G^{W T}}{H G^{N C A R}}\right)}
$$

\section{STEP III: Daily generation based on the reconstructed series}

Step III focuses on estimating the daily reconstructed series generation (Figure 3). The procedures applied in this Step are:

1) Weibull distribution (daily) [19]: for each day, the reconstructed daily wind speed and the monthly standard deviation (shape and scale parameters of Weibull distribution) are applied to define the associated distribution curve;

2) Daily generation: the Weibull distribution curve for the wind speed is applied to the selected wind turbine power curve.

\subsection{Characterization of the Reconstituted Wind Data Series}

The wind series reconstruction methodology was applied to 5 locations of interest, as shown in Table 1 . These locations, selected by state, synthesize the wind characteristics of their region, being the Northeastern coast (CE and RN), Northeastern inland (PI and BA) and South region (RS). The wind generation in South region of Brazil is characterized by lower intensity, lower annual seasonality and higher direction variability while the Northeast is characterized by higher intensity, higher annual seasonality and lower steering variability.

Table 2 presents the characterization of these series, as well as the values of the Exponent (n) of the Power Law used for the vertical extrapolation of each series and the monthly correlations.

\subsection{Reconstructed Wind Time Series}

The wind time series for each location analyzed in this study are shown in Figure 4, Figure 5, Figure 6, Figure 7 and Figure 8. In these figures, for each considered location there are two plotted graphs, where the first one refers to the raw data pairing, without treatment. The second graph represents the result of the methodology where the wind speed is plotted on a daily average basis. Figure 9

Table 1. Wind power plants locations.

\begin{tabular}{ccccc}
\hline \multirow{2}{*}{ Name } & WPP-Code & \multicolumn{2}{c}{ Coordinates $^{\mathrm{a}}\left[{ }^{\circ}\right]$} & \multirow{\text{CF}^{c}}{[\%]}{} \\
\cline { 3 - 4 } & WPP-BA & -14.0 & -42.0 & $54 \%$ \\
Caetité & LPP-CE & -4.5 & -37.7 & $53 \%$ \\
Aracati & WPP-PI & -3.0 & -41.7 & $44 \%$ \\
Parnaíba & WPP-RN & -5.1 & -36.6 & $52 \%$ \\
Macau & WPP-RS & -30.9 & -55.7 & $44 \%$ \\
\hline Coxilha Negra & Wong. & \\
\hline
\end{tabular}

a. Coordinates in World Geodetic System 1984 (WGS84); b. Codes represent WPP in their related Federal State location; c. CF-Capacity Factor. 
Table 2. Data sources.

\begin{tabular}{|c|c|c|c|c|c|c|}
\hline WPP & Source & $\begin{array}{c}\text { Time } \\
\text { Resolution }\end{array}$ & Height $^{a}$ & $(n)^{b}$ & $\begin{array}{l}\text { Common } \\
\text { Period }\end{array}$ & $\begin{array}{l}\text { Monthly } \\
\text { Correlation }\end{array}$ \\
\hline WPP-BA & $\begin{array}{c}\text { NCAR/NCEP } \\
\text { VORTEX }\end{array}$ & $\begin{array}{l}6 \mathrm{~h} / 6 \mathrm{~h} \\
\text { hourly }\end{array}$ & $\begin{array}{l}42 \mathrm{~m} \\
120 \mathrm{~m}\end{array}$ & 0.6396 & $\begin{array}{l}\text { Jan/1982 - } \\
\text { Mar/2014 }\end{array}$ & 0.8407 \\
\hline WPP-CE & $\begin{array}{c}\text { NCAR/NCEP } \\
\text { VORTEX }\end{array}$ & $\begin{array}{l}6 \mathrm{~h} / 6 \mathrm{~h} \\
\text { hourly }\end{array}$ & $\begin{array}{l}42 \mathrm{~m} \\
120 \mathrm{~m}\end{array}$ & 0.3568 & $\begin{array}{c}\text { Jan/1982 - } \\
\text { Feb/2014 }\end{array}$ & 0.9071 \\
\hline WPP-PI & $\begin{array}{c}\text { NCAR/NCEP } \\
\text { VORTEX }\end{array}$ & $\begin{array}{l}6 \mathrm{~h} / 6 \mathrm{~h} \\
\text { hourly }\end{array}$ & $\begin{array}{l}42 \mathrm{~m} \\
120 \mathrm{~m}\end{array}$ & 0.0891 & $\begin{array}{l}\text { Jan/1993 - } \\
\text { May/2015 }\end{array}$ & 0.8509 \\
\hline WPP-RN & $\begin{array}{c}\text { NCAR/NCEP } \\
\text { VORTEX }\end{array}$ & $\begin{array}{l}6 \mathrm{~h} / 6 \mathrm{~h} \\
\text { hourly }\end{array}$ & $\begin{array}{l}42 \mathrm{~m} \\
120 \mathrm{~m}\end{array}$ & 0.3440 & $\begin{array}{c}\text { Jan/1982 - } \\
\text { Feb/2014 }\end{array}$ & 0.8785 \\
\hline WPP-RS & $\begin{array}{c}\text { NCAR/NCEP } \\
\text { VORTEX }\end{array}$ & $\begin{array}{l}6 \mathrm{~h} / 6 \mathrm{~h} \\
\text { hourly }\end{array}$ & $\begin{array}{l}42 \mathrm{~m} \\
120 \mathrm{~m}\end{array}$ & 0.4779 & $\begin{array}{l}\text { Jan/1982 - } \\
\text { Mar/2014 }\end{array}$ & 0.8233 \\
\hline
\end{tabular}

a. wind turbine hub height; $b$. (n) - exponent of the wind profile power law relationship.

WPP-BA - Mesoescala data with no treatment

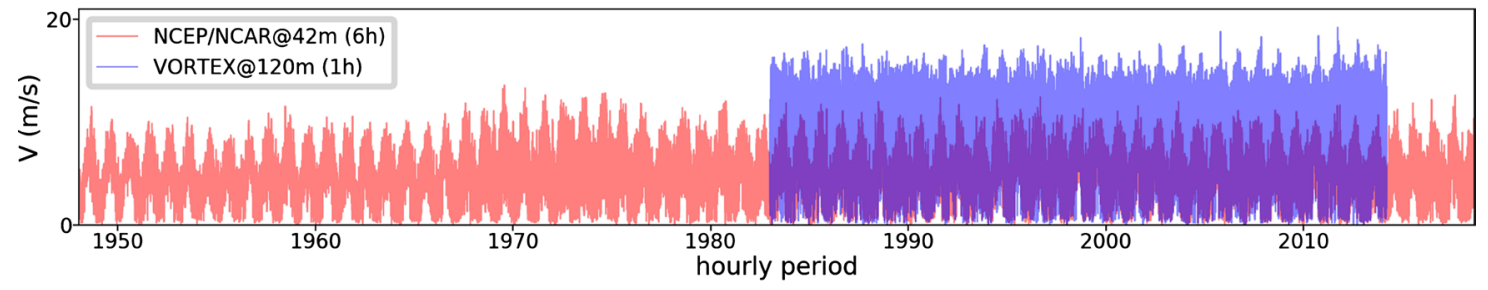

WPP-BA - Rebuilt Series

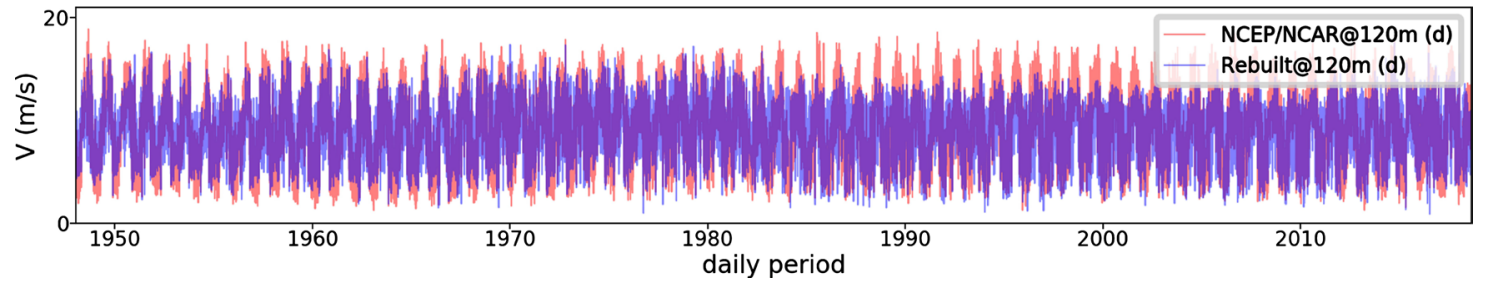

Figure 4. Methodology applied to WPP-BA.

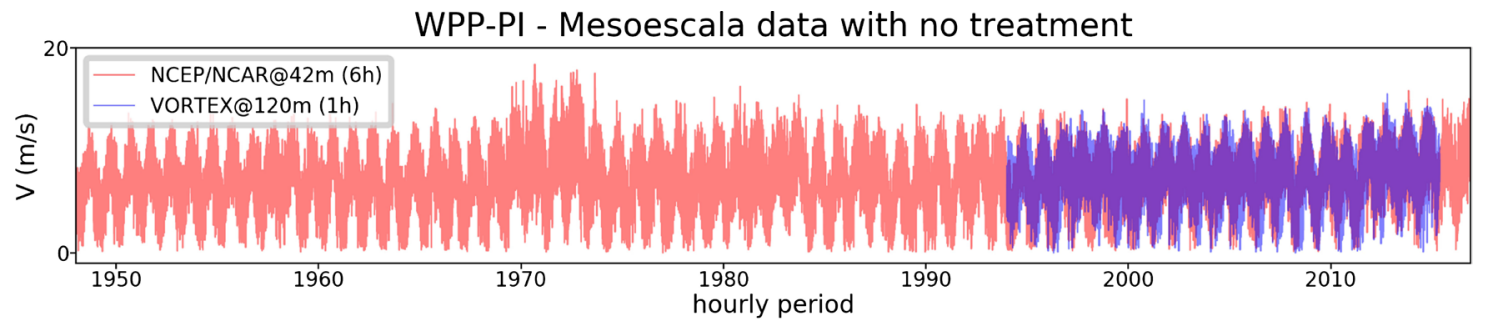

WPP-PI - Rebuilt Series

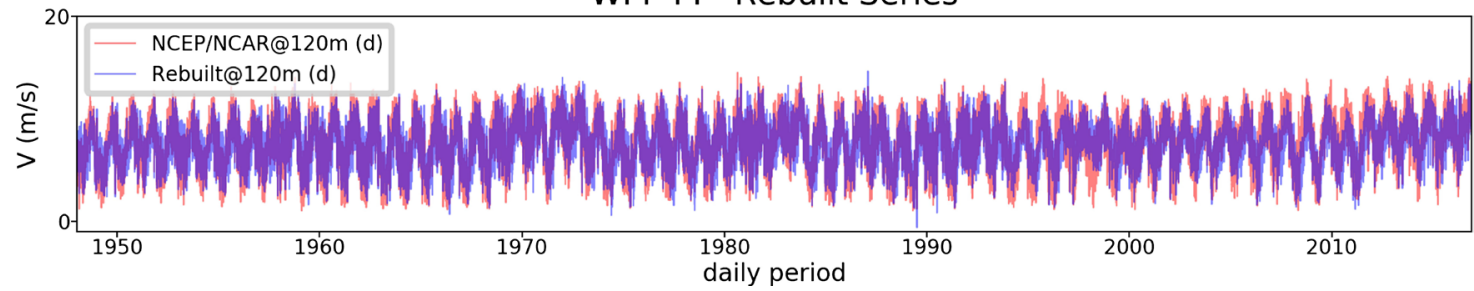

Figure 5. Methodology applied to WPP-PI. 

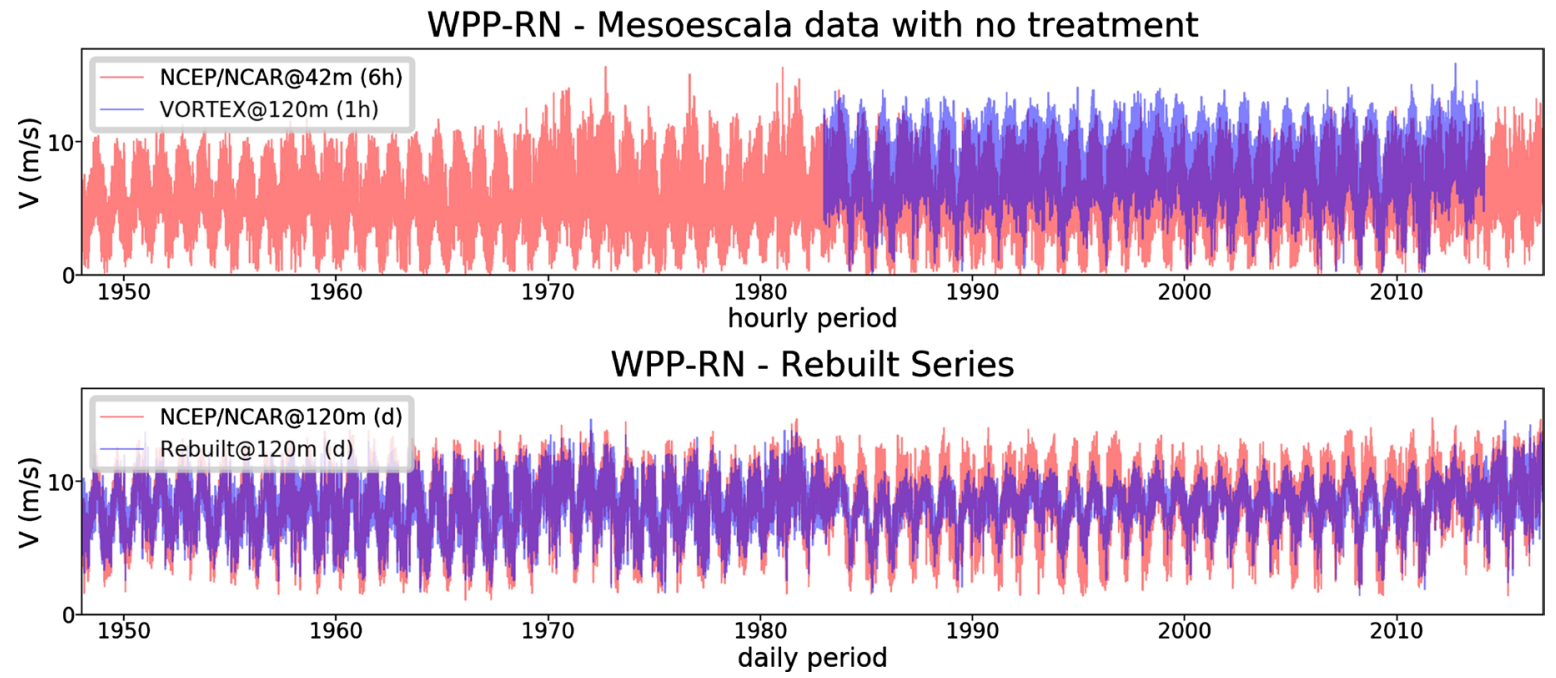

Figure 6. Methodology applied to WPP-RN.

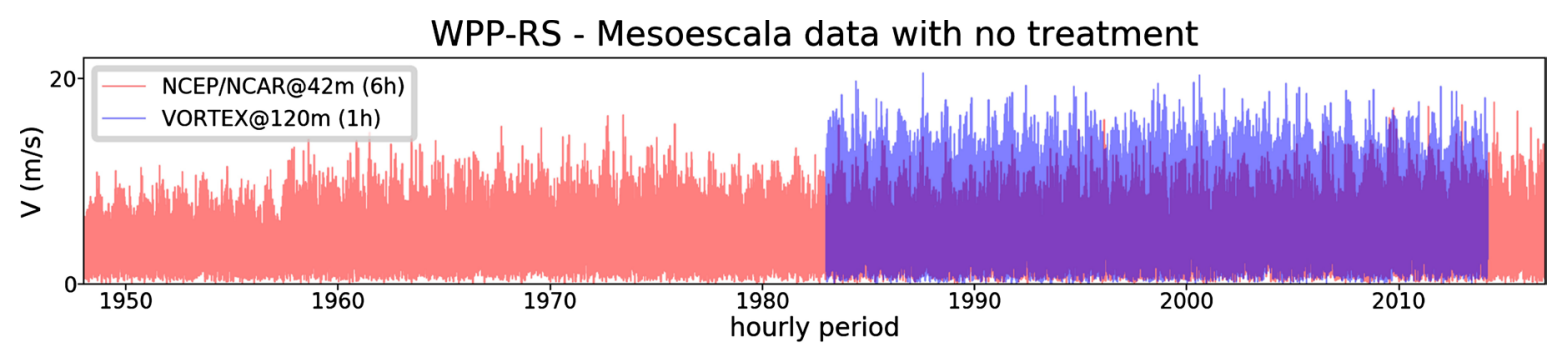

WPP-RS - Rebuilt Series

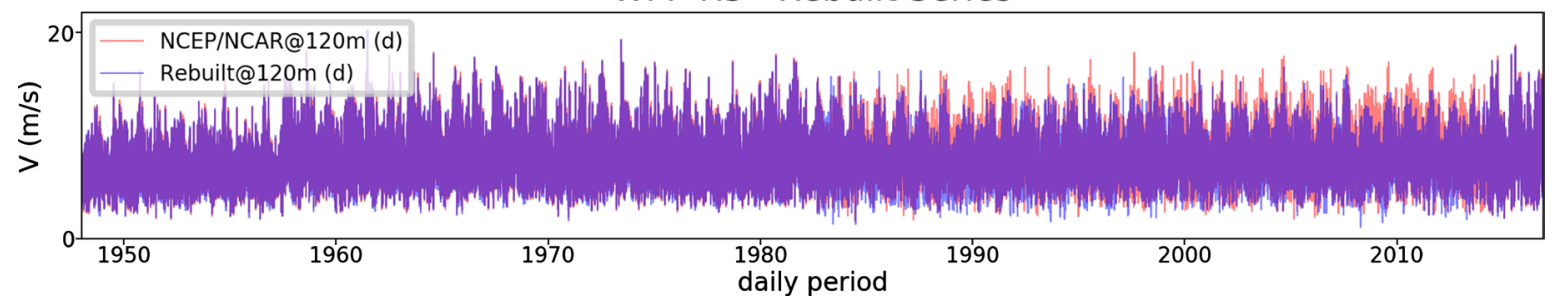

Figure 7. Methodology applied to WPP-RS.
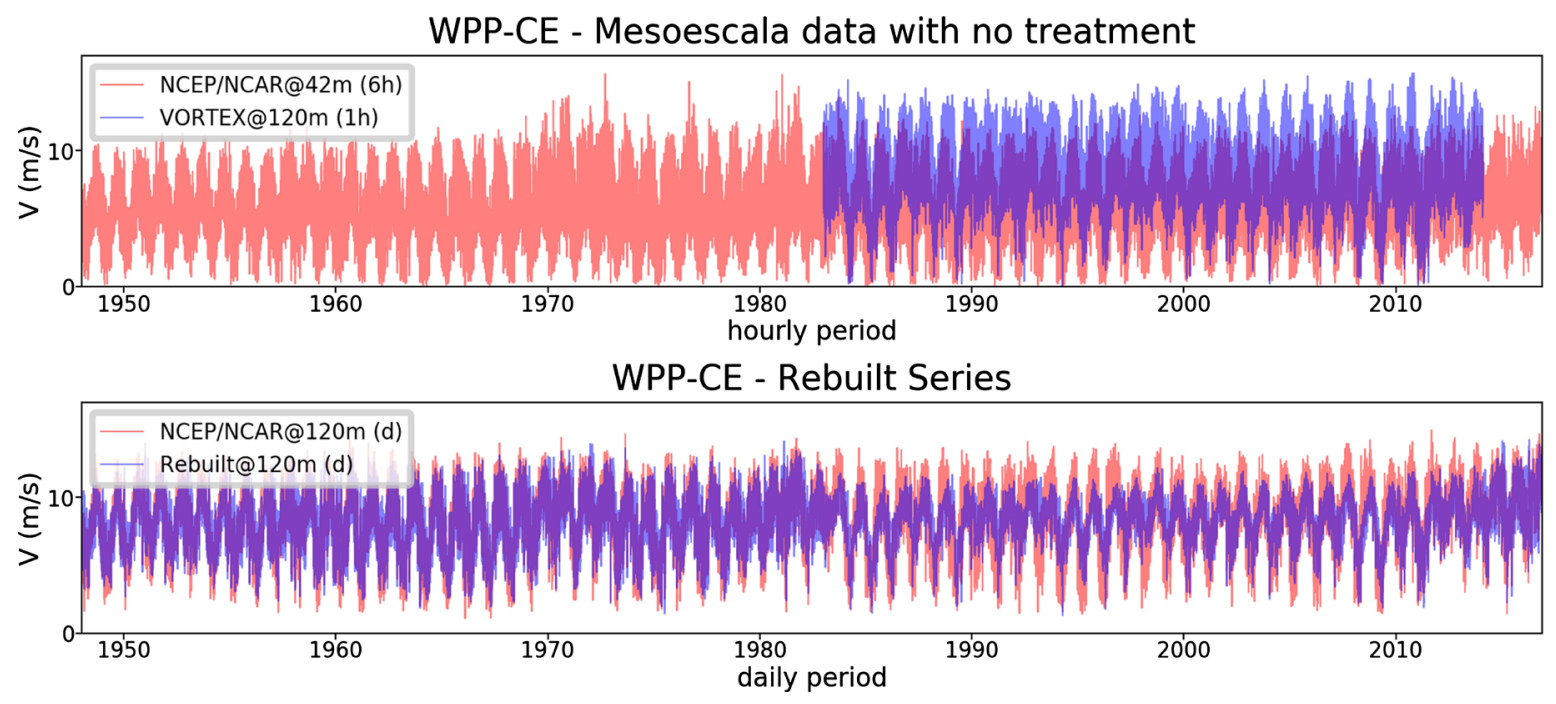

Figure 8. Methodology applied to WPP-CE. 


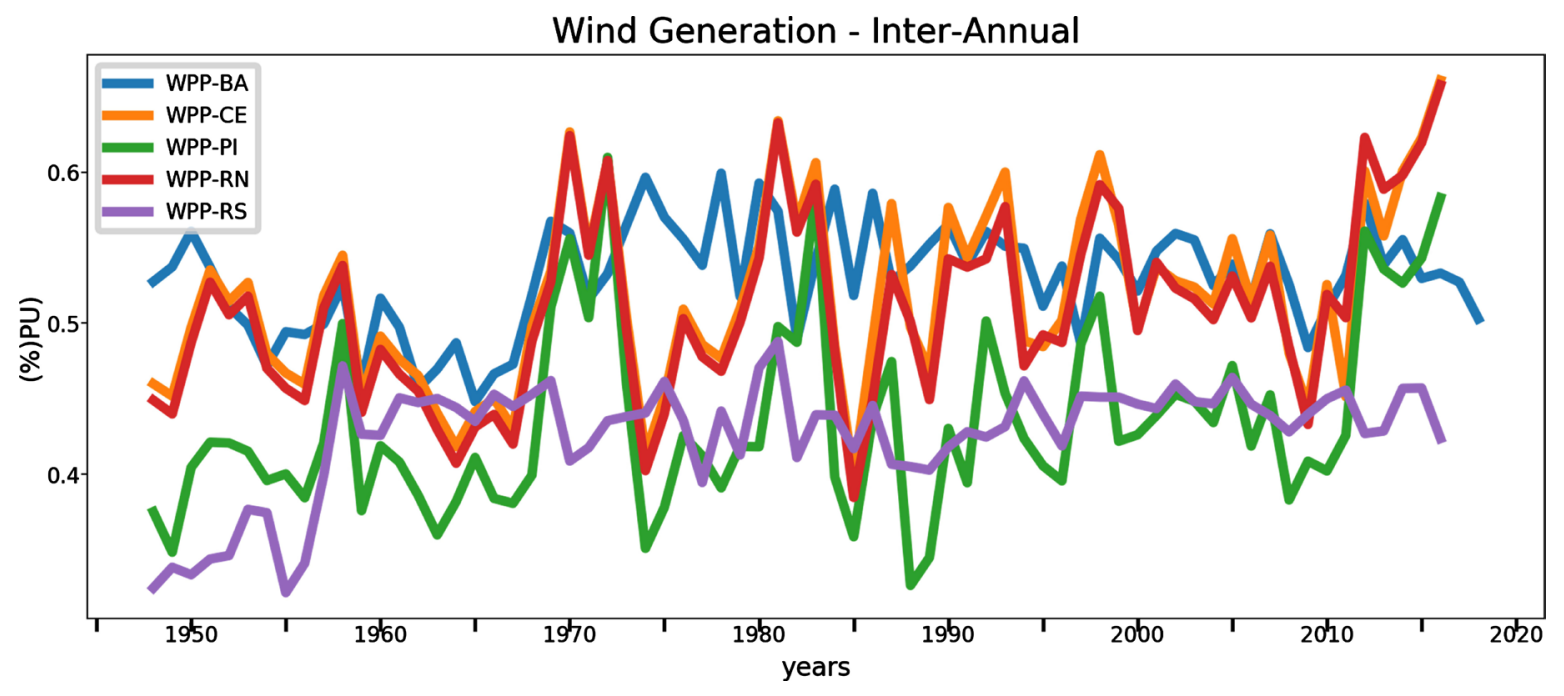

Figure 9. Comparation of wind generation reconstructed.

presents the generation results comparison between the five locations considered in this work.

The results indicate great variability of the wind speed between sites, directly influencing the generation complementarity degree, being important to observe that it is not possible to define a global standard behavior as there are different wind generation patterns. Nevertheless, sites like WPP-CE e WPP-RN show similarity although located in different places. These locations share the same Northeast coastal wind characteristics, however, they present different infrastructure restrictions that reflect on investment costs.

\section{Financial Resource Allocation for Wind Power Plants Portfolio Selection}

This work presents a new business model formulation and its application for wind power plants portfolio selection. The business model uses the concept of optimal resource allocation, meaning that given a budget cap and investment options in wind power plants, it is possible to define the optimal plant portfolio that maximizes the financial results for trading the energy produced by the whole optimum set of generation plants, considering both, the financial risk and investment return. In this model, the long-term wind time series data provided by the reconstruction methodology are used as scenarios of energy generation.

\subsection{Model Overview}

The selection of portfolios composed purely by wind power plants (WPP) can be understood as the solution of a problem characterized by to find the optimal allocation of the available financial resources for investment in one or more plants, in such a way to get financial results (risk x return) higher than those that could be obtained by fully allocating resources in a single wind project.

To carry out this kind of analysis, it is was decided to apply a stochastic risk-aversion optimization model, where the decision variables are 1) the optim- 
al composition of the wind portfolio and 2) the volume to be allocated in the portfolio selling contract.

The objective function considers the financial risk and investment return, weighted by a parameter that represents the risk aversion profile of the decision maker. The financial risk is measured by the Conditional Value-at-Risk (CVaR) metric, as defined by [20].

In Equation(3), the objective function is defined as the maximization of the convex function composed by the Expected Revenue and CVaR (risk metric), weighted by a risk aversion parameter $\rho$. In this function, the first expression inside the brackets computes the Expected Revenue while the second expression represents the main equation of CVaR. Note that in case of an agent totally risk-averse, $\rho$ is equal to $100 \%$ and the decision is only taken by accounting the financial risk (CVaR). In opposite condition, totally risk-neutral, $\rho$ is null and the decision is taken by Expected Revenue. Intermediates values of $\rho$ represent risk-aversion profiles that weight Expected Revenue and CVaR in the decision.

$$
\max \sum_{t \in T} \frac{1}{(1+r)^{t}} \cdot\left[(1-\rho) \cdot \sum_{s \in S}\left(p_{s} \cdot R_{t, s}^{P}\right)+\rho \cdot\left(A_{t}-\frac{1}{\alpha} \cdot \sum_{s \in S}\left(p_{s} \cdot a_{t, s}\right)\right)\right]
$$

In the presented equation, $r$ is the return rate, $p_{s}$ is the probability of scenario $s$ belonging to a set of $S$ scenarios, $A_{t}$ is an auxiliary variable at time $t$ belonging to a set of $T$ months in horizon planning, whose value corresponds to the Value-at-Risk within a confidence interval $\alpha \in(0,1)$, assumed 0.05 in this work. The $a_{t, s}$ is a positive auxiliary variable used to compute the CVaR at time $t$ and scenario $s$. For computing CVaR, it is necessary to consider an additional restriction defined as Equation (4):

$$
a_{t, s} \geq A_{t}-R_{t, s}^{P} ; \quad a_{t, s} \geq 0
$$

The Portfolio Revenue at time $t$ and scenario $s, R_{t, s}^{P}$, is obtained by the sum of the Variable Revenue $\left(R_{t, s}^{V}\right)$ and the Fixed Revenue $\left(R_{t}^{F}\right)$ minus the expenditure cost $\left(C^{P}\right)$ as in Equation (5):

$$
R_{t, s}^{P}=R_{t, s}^{V}+R_{t}^{F}-C_{t}^{P}
$$

As shown in Equation (6), the Variable Revenue $\left(R_{t, s}^{V}\right)$ represents the exposure risk in energy spot market, as in order to meet the selling contract the differences between the contracted energy and real generation are settled by the spot price.

$$
R_{t, s}^{V}=\left(\sum_{k \in K^{W}} G_{t, s, k}-E^{C} \cdot h_{t}\right) \cdot \pi_{t, s}^{S P}
$$

where: $G_{t, s, k}$ is the generation of each $k$ WPP in the portfolio composed by $K$ WPP at time $t$ and scenario $s, E^{C}$ is the energy committed in the selling contract, expressed in terms of avg MW (Average $\mathrm{MW}=\mathrm{MWh} /$ number of hours); $\pi_{t, s}^{S P}$ is the spot price at time $t$ and scenario $s, h_{t}$ is the number of hours in each period of time $t$. 
The Fixed Revenue $\left(R_{t}^{F}\right)$, coming from the selling contracts, is computed by multiplying the energy committed in a selling $\left(E^{C}\right)$ by its nominal price $\left(\pi_{t}^{C}\right)$ at time $t$, as indicated in Equation (7). Once the model aims to find optimal volume to be allocated in a single selling contract of the portfolio, thus $E^{C}$ represents a decision variable.

$$
R_{t}^{F}=E^{C} \cdot \pi_{t}^{C} \cdot h_{t}
$$

In Equation (8) the total capital expenditure allocated in the portfolio $\left(C^{P}\right)$ is defined as the sum of the unitary investments of the WPP in the portfolio $\left(I_{k, t}^{\prime}\right)$ by its correspondent installed capacity $\left(p t_{k}\right)$. Note that pot $_{k}$ is a decision variable that defines the participation of each WPP in the portfolio.

$$
C_{t}^{P}=\sum_{k \in K^{W}} I_{k, t}^{\prime} \cdot \text { pot }_{k}
$$

The unitary monthly investment WPP $\left(I_{k, t}^{\prime}\right)$ is represented in terms of the capital expenditure per unit of installed capacity, converted into uniform monthly payments during the planning horizon. It is obtained by applying the Annual Equivalent Cost (AEC) divided by 12 (number of months in a year), as in Equation (9).

$$
I_{k, t}^{\prime}=\frac{\left(\operatorname{CAPEX} \cdot \frac{i \cdot(1+r)^{n}}{\left((1+r)^{n}-1\right)}\right)}{12}
$$

The AEC parameter is a function of the interest rate $(r=9 \%$ p.y. $)$, power plant lifetime ( $n=25$ years) and CAPEX (Capital Expenditure, per-unit of MW installed). With this approach, the financial costs are uniformed distributed along the project lifetime.

Associated with the equations above, Equation (10) is a constraint representing that the total capital invested must be less than or equal to the available budget $\left(B^{P}\right)$, defined as model input assumption.

$$
C^{P} \leq B^{P}
$$

Another important assumption is that there is no leverage in the selling operation, meaning that the energy selling should be covered by the maximum amount of energy the portfolio can sell.

Under the Brazilian regulatory rules, the maximum amount a power plant can sell is defined by its Firm Energy Certificate (FEC). For each type of source, there is a specific rule to calculate it. In the case of wind energy, FEC is calculated based on the $90^{\text {th }}$ percentile criteria of annual generation estimated for the wind power plant, which considers three years of wind measurement, among other technical details, according to the energy certification issued by certification's companies. Therefore, the non-leverage restriction is written as Equation (11) below:

$$
E^{c} \leq \sum_{k \in K^{W}} \operatorname{pot}_{k} \cdot F E C_{k}^{\prime}
$$


Note that the FEC of each WPP depends on its own installed capacity, thus, we wrote this variable as a single multiplication of the decision variable pot $_{k}$ by the $F E C_{k}^{\prime}$, which represents a per-unit FEC of a each WPP.

The generation scenarios of each WPP $\left(G_{t, s, k}\right)$ can be described as a function of the decision variable pot $_{k}$ and the per-unit generation, $G_{t, s, k}^{\prime}$, as shown in Equation (12):

$$
G_{t, s, k}=\operatorname{pot}_{k} \cdot G_{t, s, k}^{\prime} \cdot h_{t}
$$

It is important to highlight that the variables $I_{k, t}^{\prime}, F E C_{k}^{\prime}$ and $G_{t, s, k}^{\prime}$ are expressed as per-unit of MW, assuming that these parameters behaviors can be described as linear functions for the purpose of modeling simplification.

The spot prices scenarios were obtained from a multi-stage stochastic optimization model named Newave, the official model used for operating the Brazilian Power System, characterized by being a system with centralized dispatch, whose energy price is formed through the application of models that emulate the operation of the system. For more on, see [21].

\subsection{Case Study}

The case studies aim to analyze the portfolio selection considering the five wind power plants, supported by the proposed optimization model and using the generation scenarios created by the reconstruction methodology. The five wind power plants are those previously studied in this work: Caetité-BA, Aracati-CE, Parnaíba-PI, Macau-RN, Coxilha Negra-RS.

We simulated two cases under CAPEX hypotheses: 1) a single CAPEX amount for all WPP and 2) different CAPEX for each WPP, based on historical data of Public Energy Auctions [22].

In each case we consider three risk-aversion levels $(0 \%, 50 \%, 100 \%)$ and run four portfolio configurations. As a research assumption, in each simulation round the highest-performing WPP is excluded to investigate the attractiveness of the others with the lowest performance. Thus, four sequential simulations were carried out with 5, 4, 3 and 2 WPP in the portfolio configuration.

\subsubsection{Case (i): Portfolio Selection-Same CAPEX Value for All WPP}

In the first case, considering the same single CAPEX value of 4 million $\mathrm{R} \$ \mathrm{MW}$ for all WPP, the goal was to analyze the competitiveness of wind farms under the same investment conditions, to emphasize their performance in relation to the commercialization of the energy produced by the portfolio and the complementarity of generation between the WPP.

The investment budget is assumed to be $\mathrm{R} \$ 600$ million $^{1}$, which allows to compose a portfolio up to $150 \mathrm{MW}$. The assumed price for the selling contract is 140.00 R\$/MWh.

Table 3 presents the results obtained for a risk-aversion of $0 \%$, that is, when ${ }^{1}$ Financial values are expressed in Brazilian currency Real $(\mathrm{R} \$)$, where $\mathrm{R} \$ 1000.00 \approx € 180.00 \approx \mathrm{US}$ $\$ 190.00$, according to April 2020 quotation. R\$ 600 million $\approx € 108$ million $\approx$ US\$ 114 million; 140.00 $\mathrm{R} \$ / \mathrm{MWh} \approx 25.2 € / \mathrm{MWh} \approx 26.6 \mathrm{US} \$ / \mathrm{MWh}$. 
decision is taken only the Expected Revenue is considered. In this case, there is no portfolio diversification, and, for all combinations, it is allocated $150.00 \mathrm{MW}$ in the WPP of higher capacity factor, meaning that all available budget is allocated in a unique WPP in all combinations.

In this case, the objective function considers only the expected revenue for the final decision, however, we plot the CVaR values as reference of the risk that is no being accounted in such risk-aversion condition. Another important observation is on the huge difference in the financial results among the return on Caetité (higher capacity factor) in comparison with Parnaiba (lower capacity factor).

The next simulation was performed under a risk-aversion of 50\%, where Expected Revenue and CVaR are equally weighted in the objective function.

Table 4 presents the financial results achieved, in which it is observed a diversification by considering only the two WPP of lowest capacity factors, Parnaíba $(\mathrm{CF}=44 \%)$ and Coxilha Negra $(\mathrm{CF}=44 \%)$.

As can be seen, although both WPP have the same capacity factor, the allocation was higher in the first (102.59 MW) than in the second (47.41 MW). This can be understood by the fact that the generation risk of WPP-Parnaiba is lower than the other. Therefore, when accounting for the risk $(\mathrm{CVaR})$ in the objective function, it is better to allocate more capital in the WPP-Parnaíba.

Table 5 presents the result under a risk-aversion of $100 \%$, where it is only accounted the CVaR in the objective function. Note that there is more diversification, considering portfolios composed by the combinations of 3 WPP and 2 WPP. Comparing these results with those obtained in the previous risk-aversion

Table 3. Case (i)—Portfolio Composition (MW): Risk-aversion 0\%.

\begin{tabular}{ccccccccc}
\hline & \multicolumn{3}{c}{ WPP } & & \multicolumn{3}{c}{ Financial Results (R\$million) } \\
\cline { 2 - 9 } Port. & Parnaíba & $\begin{array}{c}\text { Coxilha } \\
\text { Negra }\end{array}$ & Macau & Aracati & Caetité & $\begin{array}{c}\text { Exp. } \\
\text { Rev. }\end{array}$ & CVaR & $\begin{array}{c}\text { Result } \\
\text { (Obj. F.) }\end{array}$ \\
\hline 5 WPP & 0.00 & 0.00 & 0.00 & 0.00 & 150.00 & 159.90 & 108.73 & 159.89 \\
4 WPP & 0.00 & 0.00 & 0.00 & 150.00 & - & 145.93 & 77.93 & 145.93 \\
3 WPP & 0.00 & 0.00 & 150.00 & - & - & 135.96 & 54.37 & 135.96 \\
2 WPP & 150.00 & 0.00 & - & - & - & 58.64 & -1.15 & 58.64 \\
\hline
\end{tabular}

Table 4. Case (i) - Portfolio Selection (MW): Risk-aversion 50\%.

\begin{tabular}{|c|c|c|c|c|c|c|c|c|}
\hline \multirow{2}{*}{ Port. } & \multicolumn{5}{|c|}{ WPP } & \multicolumn{3}{|c|}{$\begin{array}{l}\text { Financial Results } \\
\left(\mathrm{R} \${ }^{*} \text { million }\right)\end{array}$} \\
\hline & Parnaíba & $\begin{array}{c}\text { Coxilha } \\
\text { Negra }\end{array}$ & Macau & Aracati & Caetité & $\begin{array}{l}\text { Exp. } \\
\text { Rev. }\end{array}$ & CVaR & $\begin{array}{l}\text { Result } \\
\text { (Obj. F.) }\end{array}$ \\
\hline $5 \mathrm{WPP}$ & 0.00 & 0.00 & 0.00 & 0.00 & 150.00 & 159.90 & 108.73 & 134.32 \\
\hline $4 \mathrm{WPP}$ & 0.00 & 0.00 & 0.00 & 150.00 & - & 145.93 & 77.93 & 111.93 \\
\hline $3 \mathrm{WPP}$ & 0.00 & 0.00 & 150.00 & - & - & 135.96 & 54.37 & 95.17 \\
\hline $2 \mathrm{WPP}$ & 102.59 & 47.41 & - & - & - & 55.23 & 9.49 & 32.36 \\
\hline
\end{tabular}


simulations, there is a decrease in the expected revenue in compensation of an increase in the CVaR value (the higher the CVaR value, the lower the risk, as the $\mathrm{CVaR}$ value becomes closer to the expected revenue value).

In all simulations, we found allocations in selling contract between 85\% $100 \%$ of the total firm energy credit of the portfolio. This pattern reflects the influence of the P90 criterion in the calculation of the FEC of wind farms, which significantly reduces the amount of energy that wind power plants can commercialize in Brazil. As a matter of organization, we have not aimed to detail this aspect in this study. For more on, see [22].

\subsubsection{Case (ii): Portfolio Selection-Different CAPEX}

The second case includes an assumption of different CAPEX unitary value for each WPP. The CAPEX is based on the historical data of Public Energy Auctions in Brazil [23] and the unitary value is represented by the historical average investments in each Federal State related to the WPP location, as shown in Table 6. Thus, it approximately reflects the cost differences in each location, given its economic particularities for developing this type of power plants.

For simulation purpose, it was assumed an investment budget of R $\$ 600$ million and a selling contract price of $140.00 \mathrm{R} \$ \mathrm{MWh}$.

In the neutral risk-aversion (0\%) simulation results, it is observed that there is no diversification (see the next Table). The only change observed is that in this case ii, WPP-Aracati becomes more valuable than Caetité, as the first has lower CAPEX than the second. Table 7 presents the results for all combinations, showing the full budget allocation in each WPP.

Considering a risk-aversion of $50 \%$ in the simulation (Table 8), there is diversification between Macau e Caetité in the 4 WPP combination, because of differences in the CAPEX of each one. In the remaining combinations, there is no diversification, as the selection includes only the WPP with greater attractiveness

Table 5. Case (i) - Portfolio Composition (MW): Risk-aversion 100\%.

\begin{tabular}{cccccccccc}
\hline & \multicolumn{4}{c}{ WPP } & \multicolumn{3}{c}{ Financial Results (R\$*million) } \\
\cline { 2 - 9 } Port. & Parnaíba & $\begin{array}{c}\text { Coxilha } \\
\text { Negra }\end{array}$ & Macau & Aracati & Caetité & Exp. Rev. & CVaR & $\begin{array}{c}\text { Result } \\
\text { (Obj. F.) }\end{array}$ \\
\hline 5 WPP & 0.00 & 0.00 & 0.00 & 0.00 & 150.00 & 159.90 & 108.73 & 108.73 \\
4 WPP & 0.00 & 0.00 & 0.00 & 150.00 & - & 145.93 & 77.93 & 77.93 \\
3 WPP & 0.00 & 25.43 & 124.57 & - & - & 121.02 & 55.22 & 55.22 \\
2 WPP & 95.98 & 54.02 & - & - & - & 54.76 & 9.77 & 9.77 \\
\hline
\end{tabular}

Table 6. Case (ii)-WPP CAPEX.

\begin{tabular}{|c|c|c|c|c|c|}
\hline WPP & Parnaíba & Coxilha Negra & Macau & Aracati & Caetité \\
\hline Federal States & Piauí & Rio Grande do Sul & $\begin{array}{l}\text { Rio Grande do } \\
\text { Norte }\end{array}$ & Ceará & Bahia \\
\hline$\left[\mathrm{R} \${ }^{*}\right.$ million/MW] & 3.60 & 4.03 & 3.95 & 3.65 & 4.08 \\
\hline
\end{tabular}


in terms of risk and return.

Under $100 \%$ of risk-aversion condition, where only CVaR is accounted, the risk profile of WPP leads to diversifications in all combinations, as it could be seen in Table 9, meaning that the optimal portfolio compositions are those that provide a higher CVaR (lower risk), in absence of considering the expected revenue in the decision.

Based on the achieved results, it should be realized that there is a trade-off in defining the portfolio selection, associated with the risk-aversion profile of the decision maker. This issue brings an important reflection on the analysis together with the currently questions related with generation profiles, trading and investment in each wind power plant.

\section{Conclusions}

Wind energy investment analysis using stochastic programming models demands to consider long-term scenarios of wind generation, to guarantee the

Table 7. Case (ii)—Portfolio Selection (MW): Risk-aversion 0\%.

\begin{tabular}{cccccccccc}
\hline & \multicolumn{3}{c}{ WPP } & & \multicolumn{3}{c}{ Financial Results (R\$*million) } \\
\cline { 2 - 9 } Port. & Parnaíba & $\begin{array}{c}\text { Coxilha } \\
\text { Negra }\end{array}$ & Macau & Caetité & Aracati & Exp. Rev. & CVaR & $\begin{array}{c}\text { Result } \\
\text { (Obj. F.) }\end{array}$ \\
\hline 5 WPP & 0.00 & 0.00 & 0.00 & 0.00 & 164.38 & 197.71 & 123.18 & 197.70 \\
4 WPP & 0.00 & 0.00 & 0.00 & 146.88 & - & 148.37 & 98.27 & 148.37 \\
3 WPP & 0.00 & 0.00 & 153.06 & - & - & 146.78 & 63.52 & 146.77 \\
2 WPP & 166.67 & 0.00 & - & - & - & 108.93 & 42.50 & 108.93 \\
\hline
\end{tabular}

Table 8. Case (ii)-Portfolio Selection (MW): Risk-aversion 50\%.

\begin{tabular}{ccccccccc}
\hline & \multicolumn{3}{c}{ WPP } & & \multicolumn{3}{c}{ Financial Results (R\$*million) } \\
\cline { 2 - 9 } Port. & Parnaíba & $\begin{array}{c}\text { Coxilha } \\
\text { Negra }\end{array}$ & Macau & Caetité & Aracati & Exp. Rev. & CVaR & $\begin{array}{c}\text { Result } \\
\text { (Obj. F.) }\end{array}$ \\
\hline 5 WPP & 0.00 & 0.00 & 0.00 & 0.00 & 164.38 & 197.71 & 123.18 & 160.45 \\
4 WPP & 0.00 & 0.00 & 21.26 & 126.48 & - & 148.15 & 98.70 & 123.43 \\
3 WPP & 0.00 & 0.00 & 153.06 & - & - & 146.78 & 63.52 & 105.15 \\
2 WPP & 166.67 & 0.00 & - & - & - & 108.93 & 42.50 & 75.72 \\
\hline
\end{tabular}

Table 9. Case (ii)—Portfolio Composition (MW): Risk-aversion 100\%.

\begin{tabular}{ccccccccc}
\hline & \multicolumn{3}{c}{ WPP } & & \multicolumn{3}{c}{ Financial Results (R\$*million) } \\
\cline { 2 - 9 } Port. & Parnaíba & $\begin{array}{c}\text { Coxilha } \\
\text { Negra }\end{array}$ & Macau & Caetité & Aracati & $\begin{array}{c}\text { Exp. } \\
\text { Rev. }\end{array}$ & CVaR & $\begin{array}{c}\text { Result } \\
\text { (Obj. F.) }\end{array}$ \\
\hline 5 WPP & 0.00 & 0.00 & 0.00 & 23.98 & 137.54 & 189.65 & 124.42 & 124.42 \\
4 WPP & 0.00 & 0.00 & 31.18 & 116.96 & - & 148.05 & 98.80 & 98.80 \\
3 WPP & 59.62 & 0.00 & 98.31 & - & - & 133.24 & 69.26 & 69.26 \\
2 WPP & 165.60 & 0.96 & - & - & - & 108.52 & 42.51 & 42.51 \\
\hline
\end{tabular}


results quality, reliability and representativeness. For this reason, the adopted methodology considers a technique addressing time series reconstruction to support the formulation of long-term wind generation scenarios.

The selection of a portfolio composed purely by wind farms can be translated as a business model in which the investor seeks to define the optimal allocation of the financial resources available for investment in one or more plants, in such a way as to get financial results higher than those that could be obtained by fully allocating resources in a single wind project.

The solution of such a problem was carried out by applying a stochastic risk-averse optimization model, so that, given an investment budget cap, it can be possible to determine the optimal portfolio formed by the adequate proportion of each candidate wind farms.

In the case studies, the conditions associated with the generation profile, firm energy credit and the installed capacity of each plant in the portfolio selection, in addition to the effect of the investment cost of each one, were accounted for.

Furthermore, the results show the model performance in terms of capital allocation for wind power plants portfolio selection under distinct boundary conditions, as well as emphasize that the diversification of the portfolio changes due to the assumed profile of the investor's risk aversion.

Although applied to the Brazilian case, this model can be customized for any location worldwide.

\section{Acknowledgements}

We gratefully acknowledge financial support from Afluente Geração de Energia Elétrica S/A (a Contour Global PLC company) through the Research and Development Project PD-05162-0001/2018 (ANEEL Code).

\section{Conflicts of Interest}

The authors declare no conflicts of interest regarding the publication of this paper.

\section{References}

[1] IRENA (2020) Renewable Capacity Statistics 2020. International Renewable Energy Agency (IRENA), Abu Dhabi. https://www.irena.org

[2] EPE (2019) Decade Energy Plan 2029. EPE, Rio de Janeiro. https://www.epe.gov.br/pt

[3] Verdejo, H., Escudero, W., Kliemann, W., Awerdin, A., Becker, C. and Vargas, L. (2016) Impact of Wind Power Generation on a Large-Scale Power System Using Stochastic Linear Stability. Applied Mathematical Modelling, 40, 7977-7987. https://doi.org/10.1016/j.apm.2016.04.020

[4] Mars, P., O’Sullivan, A. and Keppo, I. (2020) Estimating the Impact of Variable Renewable Energy on Base-Load Cycling in the GB Power System. Energy, 195, Article ID: 117041. https://doi.org/10.1016/j.energy.2020.117041

[5] Milligan, M., Kirby, B., Acker, T., Ahlstrom, M., Frew, B., Goggin, M., et al. (2015) 
Review and Status of Wind Integration and Transmission in the United States: Key Issues and Lessons Learned. NREL. https://www.nrel.gov/docs/fy15osti/61911.pdf https://doi.org/10.2172/1214995

[6] Bagatini, M., Benevit, M.G., Beluco, A. and Risso, A. (2017) Complementarity in Time between Hydro, Wind and Solar Energy Resources in the State of Rio Grande do Sul, in Southern Brazil. Energy and Power Engineering, 9, 515-526.

https://doi.org/10.4236/epe.2017.99036

[7] Cantão, M.P., Bessa, M.R., Bettega, R., Detzel, D.H.M. and Lima, J.M. (2017) Evaluation of Hydro-Wind Complementarity in the Brazilian Territory by Means of Correlation Maps. Renewable Energy, 101, 1215-1225. https://doi.org/10.1016/j.renene.2016.10.012

[8] Castro, R. and Crispim, J. (2018) Variability and Correlation of Renewable Energy Sources in the Portuguese Electrical System. Energy for Sustainable Development, 42, 64-76. https://doi.org/10.1016/j.esd.2017.10.005

[9] Vinel, A. and Mortaz, E. (2019) Optimal Pooling of Renewable Energy Sources with a Risk-Averse Approach: Implications for US Energy Portfolio. Energy Policy, 132, 928-939. https://doi.org/10.1016/j.enpol.2019.06.051

[10] Ramos, D.S., Camargo, L.A.S., Guarnier, E. and Witzler, L.T. (2013) Minimizing Market Risk by Trading Hydro-Wind Portfolio: A Complementarity Approach. 10 th International Conference on the European Energy Market (EEM), Stockholm, 27-31 May 2013, 1-8. https://doi.org/10.1109/EEM.2013.6607300

[11] Birge, J.R. and Louveaux, F. (1997) Introduction to Stochastic Programming. Springer, New York, 420.

[12] Conejo, A.J., Carrión, M. and Morales, J. (2010) Decision Making under Uncertainty in Electricity Markets. International Series in Operations Research \& Management Science 153, Springer Science + Business Media, Berlin, 540.

https://doi.org/10.1007/978-1-4419-7421-1

[13] Shapiro, A., Tekaya, W., Costa, J.P. and Soares, M.P. (2013) Risk Neutral and Risk Averse Stochastic Dual Dynamic Programming Method. European Journal of Operational Research, 224, 375-391. https://doi.org/10.1016/j.ejor.2012.08.022

[14] Mummey, J.F.C., Ramos, D.S., Sauer, I.L. and Yeh, W.G. (2017) Important Issues and Results When Considering the Stochastic Representation of Wind Power Plants in a Generation Optimization Model: An Application to the Large Brazilian Interconnected Power System. Energy and Power Engineering, 11, 320-332. https://doi.org/10.4236/epe.2019.118020

[15] Witzler, L.T., Ramos, D.S., Camargo, L.A.S. and Guarnier, E. (2016) Reconstruction of Wind Generation Historical Series Aiming at the Analysis of Energy Complementarity: Methodology and Applications. 13th International Conference on the European Energy Market (EEM), Porto, 6-9 June 2016, 1-6. https://doi.org/10.1109/EEM.2016.7521324

[16] Molin, S. (2019) Hands-On Data Analysis with Pandas. 3rd Edition, Packt Publishing Ltd., Birmingham.

[17] National Center for Atmospheric Research. NCAR, Colorado, USA. https://ncar.ucar.edu

[18] Vortex. Barcelona, Spain. https://vortexfdc.com

[19] Burton, T., Sharpe, D., Jenkins, N. and Bossanyi, E. (2001) Wind Energy Handbook. 2nd Edition, John Wiley \& Sons Ltd., Chichester. https://doi.org/10.1002/0470846062 
[20] Rockfellar, R.T. and Uryasev, S.P. (2000) Optimization of Conditional Value-at-Risk. The Journal of Risk, 2, 21-41. https://doi.org/10.21314/JOR.2000.038

[21] Tekay, W. (2013) Risk Neutral and Risk Averse Approaches to Multistage Stochastic Programming with Applications to Hydrothermal Operation Planning Problems. $\mathrm{PhD}$ Thesis, School of Industrial and Systems Engineering, Georgia Institute of Technology, Atlanta.

[22] Camargo, L.A.S. (2015) Commercialization and Investment Strategy, with Emphasis on Renewable Energy, Supported by Specialized Optimization Models for Stochastic Risk X Return Assessment. Ph.D. Thesis, Polytechnique School University of São Paulo, São Paulo. (In Portuguese)

[23] CCEE (2020) The Chamber of Commercialization of Electric Energy. http://ccee.org.br 